\title{
De rol van kindkenmerken op de relatie tussen voedingspraktijken van ouders en het eet- en drinkgedrag van kinderen.
}

De rol van geslacht, BMI, temperament en slaapduur

\author{
Sanne te Brinke \\ Maastricht University \\ Faculty of Health, Medicine and Life sciences \\ stebrinke@live.nl
}

\section{Samenvatting}

Achtergrond: Het aantal kinderen met overgewicht is in de periode van 1980 tot 2009 gestegen. In Nederland had 14\% van de kinderen overgewicht in 2009 (Schönbeck et al., 2011). Wanneer een kind overgewicht heeft stijgt het risico voor verschillende ziekten, zoals diabetes, kanker of hart- en vaatziekten. The ouders van een kind hebben een invloed op het gewicht van hun kind. Door het eet- en drinkgedrag van een kind te beinvloeden, kunnen ze het gewicht van een kind bevinvloeden. Ouders kunnen met verschillende voedingspraktijken invloed hebben op het eet- en drinkgedrag van het kind: beloning, emotioneel eten geven, controle of druk uitoefenen. Methode: Het onderzoek vindt plaats binnen de KOALA studie. Deze studie is een prospectief cohort onderzoek dat is gestart in 2002. De ouders van kinderen vullen verschillende vragenlijsten. Voor dit onderzoek hebben ouders een vragenlijst ingevuld over voedingspraktijken (zoals controle, beperking en druk uitoefenen). Verder hebben de ouders een vragenlijst ingevuld over de eet- en drinkgewoontes van het kind en het temperament van het kind. Aan de hand van linieare regessieanalyses is gekeken of er een verband bestaat tussen het eeten drinkgedrag van het kind en de voedingspraktijken van ouders. Ten slotte is de rol van de moderator bekeken door regressie analyses. Resultaten: Het onderzoek laat zien dat verschillende voedingspraktijken een verband hebben met het eet- en drinkgedrag van het kind. Emotioneel eten geven, beperking van voedsel en covert controle (wanneer het kind de controle niet ervaart) hebben een gunstig verband met het eet- en drinkgedrag van het kind (gezonde inname stijgt en/of ongezonde inname daalt). Aan de andere kant 
laten de voedingspraktijken beloning en druk uitoefenen een ongunstig verband zien (de ongezonde inname stijgt en/of gezonde inname daalt). Verder werd geslacht, BMI, temperament en slaapduur als een moderator op het verband gevonden. Conclusie: Deze studie laat een gunstig en ongunstig verband zien tussen voedingspraktijken van ouders en het eet- en drinkgedrag van het kind. Verder wordt de modererende rol aangetoond van geslacht, BMI, temperament en slaapduur. Deze informatie kan gebruikt worden om tailored interventies te ontwikkelen.

\section{Keywords}

Voedingspraktijken van ouders, eetgedrag van kinderen, drinkgedrag van kinderen, kindkenmerken.

\section{Introductie}

De rol van ouders

De omgevingsfactoren hebben invloed op het ontwikkelen van overgewicht (Gezondheidsraad, 2010). Tot de omgevingsfactoren behoort de rol van de ouders in de thuissituatie. De regels die ouders stellen omtrent voeding aan kinderen, zijn van invloed op het krijgen van overgewicht bij kinderen (Swinburn, Egger \& Raza, 1999). Dit is een voorbeeld van een voedingspraktijk die een ouder gebruikt om het eet- en drinkgedrag van het kind te beïnvloeden. Ouders kunnen verschillende voedingspraktijken gebruiken (figuur 1). Ouders kunnen controle uitoefenen op het kind. Deze controle kan door het kind worden ervaart of de controle kan onzichtbaar blijven (covert controle). Het uitoefenen van covert controle zorgt voor een vermindering van inname van ongezonde producten bij kinderen (Ogden, Reynolds \& Smith, 2006). Wanneer voedsel wordt gebruikt als beloning, gaan kinderen dit voedsel meer waarderen (Birch, Zimmerman \& Hund, 1981). Verder heeft beloning een nadelig effect op de snackconsumptie van het kind (Sleddens, Kremers, Stafleu, Dagnelie, de Vries \& Thijs, 2014). Terwijl Carnell \& Wardle (2007) deze associatie niet konden vinden.

\section{De rol van kindkenmerken}

De hierboven beschreven studies laten verschillende resultaten zien in de relatie tussen voedingspraktijken en overgewicht. Het is van belang om dit nogmaals te onderzoeken. Het verband tussen voedingspraktijken en het eetgedrag van het kind is verschillend in de onderzoeken. Het kan zijn dat het verband voor subgroepen verschillend is van elkaar. Dit wordt een interactie genoemd (Groenwold, 2012). Om te onderzoeken of het verband tussen voedingspraktijken van ouders en het eetgedrag van het kind verschillend is voor 
verschillende subgroepen, wordt de moderator 'kindkenmerken' onderzocht. Geslacht wordt onderzocht als moderator. Verschillende studies laten verschillende resultaten zien (Faith, Scanlon, Birch \& Sherry, 2004; Gubbels et al., 2011). Verder wordt BMI, temperament en slaapduur meegenomen als moderator. Onderzoek laat zien dat ouders meer controle uitoefenen bij kinderen met een hogere BMI (Gubbels et al., 2014). Verder laat onderzoek de relatie tussen het temperament van het kind en ouderschap zien (Gallagher, 2002). Om dit verder te onderzoek, wordt temperament onderzocht. Tenslotte wordt slaapduur als mogelijke moderator meegenomen aangezien kinderen met een kortere nachtrust een verminderd prestatievermogen hebben (Dewald, Meijer, Oort, Kerkhof \& Bögels, 2010). Bij deze kinderen valt het te verwachten dat ze door het verminderd prestatievermogen minder goed luisteren naar hun ouders.

\section{Het model}

In deze studie wordt gekeken naar de relatie tussen voedingspraktijken van ouders en het eet- en drinkgedrag van het kind (figuur 1, pijl A). Tenslotte wordt gekeken naar de rol van de moderator kindkenmerken (figuur 1, pijl B).

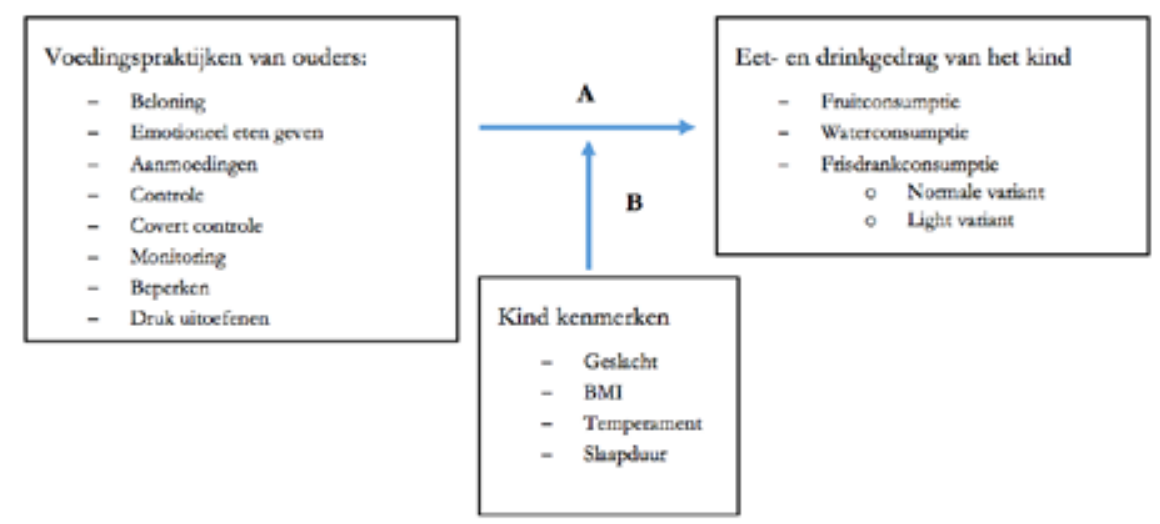

Figuur 1. Relatie tussen voedingspraktijken en eetgedragen met moderator kindkenmerken.

\section{Methode}

Deze studie heeft plaatsgevonden binnen de KOALA studie. Deze studie is in 2002 gestart met het verzamelen van gegevens bij zwangere vrouwen. KOALA staat voor Kind, Ouders en gezondheid: Aandacht voor Leefstijl en Aanleg. Het eerste doel was om aan de hand van leefstijlfactoren atopische ziekten te onderzoeken. Deelnemers bestaan uit twee 
groepen. De eerste groep betreft deelnemers $(n=2343)$ met een conventionele levensstijl. In de tweede groep zitten deelnemers $(n=491)$ met een alternatieve levensstijl. Hierbij valt te denken aan alternatieve wijze van eetgewoonten, vaccinatie en antibiotica gebruik of het groot brengen van kinderen. De KOALA studie is een prospectief cohort onderzoek (Kummeling et al., 2005).

\section{Onderzoeksopzet}

Ouders binnen de KOALA studie werden gevraagd om een vragenlijst in te vullen van hun kind in de leeftijd van 5-8 jaar. Van het oorspronkelijk cohort $(n=2843)$ zijn vragenlijsten ingevuld van 1809 kinderen. De vragenlijst ging over algemene aspecten van het kind, zoals leeftijd en gewicht. Verder werd ook gevraagd naar voeding, beweging, voedingsgedrag, gewoonte, opvoeding, huidklachten, piepende ademhaling en neusklachten. Bepaalde delen van deze vragenlijsten zijn gebruikt voor het huidige onderzoek. De variabelen die voor dit huidige onderzoek van toepassing zijn, worden hieronder uitgelegd.

\section{Variabelen}

Voor de voedingspraktijken van de ouders zijn verschillende vragenlijsten gebruikt. Voor het meten van de voedingspraktijken is de vragenlijst 'Parental Feeding Style Questionnaire' (PFSO) gebruikt. Deze vragenlijst is vertaald naar het Nederlands (Sleddens, Kremers, De Vries \& Thijs, 2010). De PFSO is een gevalideerde vragenlijst waarin vier aspecten van voedingspraktijken worden gemeten met 27 items; beloning, controle, emotioneel eten geven en aanmoedigen (Wardle et al., 2002). De cronbach's alfa van de verschillende items zijn voldoende. Bij een waarde groter dan 0.5 wordt de cronbach's alfa als voldoende gezien (Portney \& Watkins, 2000). Ook is bij het ontwikkelen van de vragenlijst de 'Child Feeding Questionnaire' (CFO) gebruikt (Birch et al., 2001). Deze vragenlijst is vertaald naar het Nederlands. In totaal worden hiervan 9 items gebruikt. Deze 9 items zijn verdeeld over 3 groepen: monitoring ( 1 items), druk uitoefenen om te eten ( 4 items) en beperken ( 4 items). Tenslotte wordt de rol van covert controle meegenomen. Van 'covert' controle is sprake wanneer een kind niet opmerkt dat er controle wordt uitgeoefend met betrekking tot het eet- en drinkgedrag (Ogden et al. 2006). De eerste moderator die wordt meegenomen is het geslacht van het kind. Het geslacht is in de studie al bekend. Dit is bij aanvang van de studie genoteerd.

Verschillende moderatoren zijn meegenomen. De eerste moderator is geslacht. Deze is bij aanvang van de studie al bekend. Verder wordt de BMI van het kind meegenomen als mogelijk moderator. De BMI van het kind wordt berekend op basis van de lengte en het 
gewicht van het kind. De metingen werden door de ouders verricht, waarbij de kinderen de schoenen uit hadden en de kleren aan. De BMI van het kind wordt op basis van z-scores meegenomen aangezien de BMI afhankelijk is van leeftijd en geslacht. Aan de hand van de z-score valt te zien of een kind ondergewicht, normaalgewicht of overgewicht heeft (Freriks, van Buuren, Wit \& Verloove-Vanhorick, 2000). Het derde kindkenmerk dat wordt meegenomen is temperament. De 'Child Behavior Questionnaire' is gebruikt om deze kenmerken te meten binnen KOALA. Deze vragenlijst bestaat oorspronkelijk uit 195 items. Een 'very short form' (VSF) is ontwikkeld die bestaat uit 36 items. In deze 36 items wordt het temperament van het kind bekeken. Het temperament wordt op 3 dimensie gemeten: extraversie, negatieve affect en 'effortful control'. Tenslotte is het slaapgedrag van het kind gemeten aan de hand van de slaapduur in minuten. Aan de ouders werd gevraagd hoelang het kind gemiddeld per dag sliep in de afgelopen 4 weken. Ouders konden hierop antwoord geven door de uren en minuten in te vullen. Hieruit kan berekend worden hoeveel minuten een kind gemiddeld per dag sliep in de afgelopen 4 weken.

Het eet- en drinkgedrag van de kinderen is meegenomen. Van verschillende soorten drinken konden ouders aangeven hoeveel het kind daarvan dronk. De volgende dranken werden meegenomen: 'water', 'frisdrank' en 'light frisdrank'. Het eetgedrag werd bekeken aan de hand van de fruitconsumptie.

Tijdens het onderzoek is voor verschillende confounders gecorrigeerd: deelnemerscohort, geboortegewicht, leeftijd van de moeder op de uitgetelde datum, de hoogste opleiding van de moeder ten tijden van de zwangerschap en het geboorteland van de vader en het geboorteland van de moeder.

\section{Data-analyse}

Voor het analyseren van de data is gebruik gemaakt van SPSS 21.0. Allereerst werd begonnen met het bekijken van de data.Vervolgens werden beschrijvende analyses gedaan waarbij gemiddelden worden berekend en wordt gekeken naar de standaarddeviaties van alle concepten. Ook wordt een Cronbach's Alfa berekend voor de interne consistentie bij de volgende concepten: controle, emotioneel eten geven, beloning, aanmoedigen, druk om te eten, 'covert' control, beperking, monitoring, extraversie, negatieve affect en 'effortful' controle. Vervolgens wordt een correlatietabel gemaakt. Vervolgens wordt een lineaire regressie uitgevoerd met als onafhankelijke variabele 'voedingspraktijken' en de afhankelijke variabele 'eetgedrag/drinkgedrag van het kind'. Hierbij worden ook de moderatoren en mogelijke confounders meegenomen. Volgens worden de moderatoren 
meegenomen. De interactietermen worden opgenomen in de modellen. Wanneer een interactie significant is wordt aan de hand van strata gekeken hoe deze interactie eruit ziet.

\section{Resultaten}

Van de 1809 kinderen die meededen aan dit onderzoek was $51.1 \%$ een jongen en $48.9 \%$ een meisje. Van alle deelnemende kinderen was $81.1 \%$ geworven via conventionele kanalen en $18.5 \%$ geworven via alternatieve kanalen. De vragenlijst is in de meerderheid van de gevallen ingevuld door de biologische moeder (95.6\%). Verder kan de vragenlijsten ingevuld zijn door de biologische vader (2.2\%). In de overige gevallen (2.2\%) is de vragenlijst ingevuld door een ander persoon dan de vader of moeder. Hierbij kan gedacht worden aan de verzorger, de opa/oma of de oom/tante van het kind. Het hoogste opleidingsniveau van de moeder ten tijde van de zwangerschap is opgedeeld in laag (3.8\%), midden (41.3\%) en hoog (51.2\%). Een aantal deelnemers ( $N=64)$ gaven aan een 'andere' opleiding te doen dan de 3 voorgenoemde (3.6\%). Tenslotte is het merendeel van de vaders (94.6\%) en moeders (95.3\%) geboren in Nederland. De kinderen aten gemiddeld 8.69 (SD = 6.34) stukken fruit in de week. Verder dronken ze gemiddeld $8.93(\mathrm{SD}=8.76)$ glazen water in de week. Het aantal glazen frisdrank wat een kind in de week dronk was 1.81 (SD = 4.60). De light-versie van frisdrank werd minder geconsumeerd dan de 'normale' frisdrank. Kinderen dronken gemiddeld $0.60(S D=2.36)$ glazen frisdrank light per week.

\section{Correlatie}

Bijna alle voedingspraktijken zijn significant gecorreleerd met een of meerdere eet- en drinkgedragingen van het kind. De voedingspraktijken 'beloning', 'emotioneel voeden' en 'monitoring' zijn met geen enkele eet-/drinkgedragingen van het kind gecorreleerd.

\section{Associatie}

Voor het analyseren van de relatie tussen voedingspraktijken en het eet- en drinkgedrag van het kind worden gestandaardiseerde beta's gebruikt. Deze gestandaardiseerde beta's lopen van -0.17 tot 0.09. Het verband tussen de voedingspraktijk beloning en fruitconsumptie is significant. Het verband tussen tussen beperken en de fruitconsumptie is negatief. Verder heeft emotioneel voeden een positief verband met de fruitconsumptie van het kind. Tenslotte heeft beperken 4 een positieve invloed op het drinkgedrag van het kind. 


\section{Modererende rol kindkenmerken}

Verschillende interacties met kindkenmerken zijn gevonden op de relatie tussen voedingspraktijken en het eet- en drinkgedrag van het kind (tabel 1). Deze interacties waren in 8 gevallen in een of meer strata van de moderator variabele significant. Deze staat aangegeven met een dikgedrukte lijn.

Tabel 1. interactie analyse tussen eet- en drinkgedrag en voedingspraktijken met moderator kindkenmerken

\begin{tabular}{|c|c|c|c|c|c|}
\hline & & $\begin{array}{l}\text { Interactie term } \\
\text { (voedingspraktijken } \mathrm{x} \text { kindkenmerk) }\end{array}$ & $\mathbf{N}$ & Beta & P-waarde \\
\hline \multirow[t]{2}{*}{ Eetgedrag } & Fruit & Aanmoedigen x BMI & 951 & 0.70 & 0.014 \\
\hline & & Emotioneel voeden x Slaapduur & 951 & 0.90 & 0.015 \\
\hline \multirow[t]{15}{*}{ Drinkgedrag } & Water & Emotioneel voeden $x$ Geslacht & 882 & 0.28 & 0.018 \\
\hline & & $\begin{array}{l}\text { Aanmoedigen } x \text { Temperament - } \\
\text { extraversie }\end{array}$ & 882 & -0.99 & 0.006 \\
\hline & & $\begin{array}{l}\text { Aanmoedigen } x \text { Temperament - } \\
\text { negatieve affect }\end{array}$ & 882 & 0.61 & 0.047 \\
\hline & & Controle $\times$ Slaapduur & 882 & 1.12 & 0.037 \\
\hline & Frisdrank & Beperken Vraag 5 x Geslacht & 912 & -2.22 & 0.015 \\
\hline & & Aanmoedigen $\times \mathrm{BMI}$ & 912 & -2.20 & 0.028 \\
\hline & & $\begin{array}{l}\text { Beperken Vraag } 11 \text { x Temperament - } \\
\text { negatieve affect }\end{array}$ & 912 & -0.51 & 0.047 \\
\hline & & $\begin{array}{l}\text { Beperken Vraag } 11 \text { x Temperament - } \\
\text { effortful control }\end{array}$ & 912 & 0.65 & 0.031 \\
\hline & Frisdrank & Aanmoedigen $\times$ Geslacht & 955 & -0.68 & 0.013 \\
\hline & Light & Beperken Vraag 3 × BMI & 955 & 0.46 & 0.039 \\
\hline & & Beperken Vraag 5 × BMI & 955 & 0.21 & 0.022 \\
\hline & & Druk uitoefenen x BMI & 955 & -0.34 & 0.028 \\
\hline & & $\begin{array}{l}\text { CovertControle x Temperament - } \\
\text { extraversie }\end{array}$ & 955 & -0.42 & 0.044 \\
\hline & & $\begin{array}{l}\text { Aanmoedigen } \mathrm{x} \text { Temperament - } \\
\text { negatieve affect }\end{array}$ & 955 & 0.66 & 0.031 \\
\hline & & $\begin{array}{l}\text { Druk uitoefenen } x \text { Temperament- } \\
\text { negatieve affect }\end{array}$ & 955 & 0.62 & 0.001 \\
\hline
\end{tabular}

Noot: gestandaardiseerde beta coëfficiënt; gecorrigeerd voor deelnemerscohort, geboortegewicht, leeftijd van moeder op uitgetelde datum, hoogste opleiding van moeder ttv zwangerschap, geboorteland moeder en geboorteland vader; $B M I=$ Body Mass Index 


\section{Discussion/Conclusion}

De huidige studie laat de modererende rol van geslacht, BMI, temperament en slaapduur zien op de relatie tussen verschillende voedingspraktijken en het eet-/drinkgedrag van het kind.

Het huidige onderzoek heeft zwakke en sterke punten. Een sterk punt is dat het onderzoek plaats vindt binnen de KOALA studie wat als positief punt heeft dat het prospectieve cohort groot is. Een zwak punt is dat de vragenlijst op één bepaald punt wordt ingevuld. Causaliteit aantonen is niet mogelijk. Verder is een ander zwak punt dat de ouders geneigd zijn sociaal wenselijke antwoorden te geven. Een ander sterk punt in het onderzoek is de gelijke verdeling van jongens en meisjes die deelnemen. Daarentegen is de verdeling erg scheef bij het invullen van de vragenlijsten over de kinderen. Het merendeel van de invullers zijn de moeders. Het laatste zwakke punt van het onderzoek is dat het eet- en drinkgedrag van het kind niet volledig in kaart is gebracht. Voor het eetgedrag is alleen gekeken naar de fruitconsumptie.

Het huidige onderzoek laat zien dat voedingspraktijken een invloed hebben op het eet- en drinkgedrag van het kind. Deze voedingspraktijken kunnen associëren met een gunstig gedrag of een ongunstig gedrag van het kind. De voedingspraktijken emotioneel eten geven, covert controle en beperken 4 zorgen voor een gunstig gedrag (gezonde inname stijgt en ongezonde inname daalt). Echter zorgen bepaalde voedingspraktijken voor een ongezondere inname waarbij de gezonde inname daalt. Deze voedingspraktijken zijn beperken 3, belonen en druk uitoefenen.

\section{Rol van de student}

Bij aanvang van de thesisperiode waren verschillende onderwerpen beschikbaar. Dit onderwerp sprak mij door de factor overgewicht en de invloed van ouder op hun kinderen. Het onderwerp en het onderzoek was al beschikbaar. De verschillende factoren zijn aan de hand van mijn eigen literatuurstudie vastgesteld. Verder waren de vragenlijst al beschikbaar. Deze werden door mijzelf geanalyseerd met SPSS. Vervolgens is het thesis paper geschreven door mij. 


\section{References}

1. Birch, L.L., Zimmerman, S.I. \& Hind, H. (1981). The influence of social-affective context on the formation of children's food preferences. Journal of Nutrition Education, 13(1), S115-S118.

2. Birch, L.L., Fisher, J.O., Grimm-Thomas, K., Markey, C.N., Sawyer, R. \& Johnson, S.L. (2001). Confirmatory factor analysis of the Child Feeding Questionnaire: a measure of parental attitudes, beliefs, and practices about child feeding and obesity proneness. Appetite, 36, 201-210.

3. Carnell, S. \& Wardle, J. (2007). Measuring behavioural susceptibility to obesity: validation of the child eating behaviour questionnaire. Appetite, 48(1), 104-113.

4. Dewald, J.F., Meijer, A.M., Oort, F.J., Kerkhof, G.A. \& Bögels, S.M. (2010). The influence of sleep quality, sleep duration and sleepiness on school performance in children and adolescents: A meta-analytic review. Sleep Medicine Reviews, 14(3), 179-189.

5. Faith, M.S., Scanlon, K.S., Birch, L.L., Francis, L.A. \& Sherry, B. (2004). Parent-Child Feeding Strategies and Their Relationship to Child Eating and Weight Status. Obesity research, 12(11), 1711-1722.

6. Fredriks, A.M., van Buuren, S., Wit, J.M. \& Verloove-Vanhorick, S.P. (2000). Body index measurements in 1996-7 compared with 1980. Archives of Disease in Childhood, 82(2), 107-112.

7. Gallagher, K.C. (2002). Does child temperament moderate the influence of parenting on adjustment? Developmental Review, 22, 623-643.

8. Gezondheidsraad. (2010). Voor dik en dun. Preventie van overgewicht en obesitas en het risico op eetstoornissen. Den Haag: Gezondheidsraad

9. Groenwold, R.H.H. (2012). Verstoring in observationeel onderzoek: 'confounding'. Nederlands Tijdschrift voor Geneeskunde, 13, 1-6.

10. Gubbels, J.S., Kremers, S.P.J., Stafleu, A., de Vries, S.I., Goldbohm, R.A., Dagnelie, P.C. et al. (2011). Association between parenting practices and children's dietary intake, activity behavior and development of body mass index: the KOALA Birth Cohort Study. International Journal of Behavioral Nutrition and Physical Activity, 8(18), 1-13.

11. Kummeling, I., Thijs, C., Penders, J., Snijders, B.E.P., Stelma, F., Reimerink, J. et al. (2005). Etiology of atopy in infancy: The KOALA Birth Cohort Study. Pediatric Allergy and Immunology, 16(8), 679-684.

12. Portney, L.G. \& Watkins, M.P. (2000). Foundations of clinical research: Applications to practice. New Jersey: Prentice Hall.

13. Ogden, J., Reynolds, R. \& Smith, A. (2006). Expanding the concept of parental control: A role for overt and covert control in children's snacking behaviour? Appetite, 47(1), 100-106.

14. Schönbeck, Y., Talma, H., van Dommelen, P., Bakker, B., Buitendijk, S.E., HiraSing, R.A. et al. (2011). Increase in Prevalence of Overweight in Dutch Children and Adolescents: A comparison of Nationwide Growth Studies in 1980, 1997, 2009. PLoS ONE, 6(11), 1-8.

15. Sleddens, E.F.C., Kremers, S.P.J., De Vries, N.K. \& Thijs, C. (2010). Relationship between parental feedingstyles and eating behaviours of Dutch children aged 6-7. Appetite, 54(1), 30-36. 
16. Sleddens, E.F.C., Kremers, S.P.J., Stafleu, A., Dagnelie, P.C., de Vries, N.K. \& Thijs, C. (2014). Food parenting practices and child dietary behavior. Prospective relations and the moderating role of general parenting. Appetite, 79, 42-50.

17. Swinburn, B., Egger, G. \& Raza, F. (1999). Dissecting Obesogenice Environments: The Development and Application of a Framework for Identifying and Prioritizing Environmental Interventions for Obesity. Preventive Medicine, 29(6), 563-570.

18. Wardle, J., Sanderson, S., Guthrie, C.A., Rapoport, L. \& Piomin, R. (2002). Parental Feeding Style and the Inter-generational Transmission of Obesity Risk. Obesity Research, 10(6), 453-462. 